\title{
The Influence of Coaches' Instruction on Technical Actions, Tactical Behaviour, and External Workload in Football Small-Sided
} Games

\author{
Jorge Batista ${ }^{1,2,3}$, Bruno Goncalves ${ }^{2,4}$, Jaime Sampaio ${ }^{2,4}$, Julia Castro ${ }^{1,2}$, Eduardo Abade ${ }^{1,2}$, \\ Bruno Travassos ${ }^{2,3}$
}

\begin{abstract}
Affiliations: 'University Institute of Maia, Department of Physical Education and Sports Sciences (ISMAI), Maia, Portugal, ${ }^{2}$ Research Centre in Sports Sciences, Health Sciences and Human Development (CIDESD), Vila Real, Portugal, ${ }^{3}$ Universidade da Beira Interior, Department of Sport Sciences, Covilhã, Portugal, ${ }^{4}$ Universidade de Trás-os-Montes e Alto Douro, Department of Sport Sciences, Exercise and Health, Vila Real, Portugal
\end{abstract}

Correspondence: B. Travassos, Universidade da Beira Interior, Sport Sciences Department, Convento de Sto António, 62001-001 Covilhã, Portugal. E-mail: bruno.travassos@ubi.pt

ABSTRACT This study aimed to explore the effects of previous instruction on technical, tactical and external workload performances in football small-sided games. Two 7-a-side balanced competitive teams received instructions regarding the rules of the small-sided games proposed. Additionally, one team received instructions from the coach regarding the collective tactical behaviour required for each exercise condition: (a) Without strategic instruction (WSI); (b) Defensive strategy (DS); (c) Offensive strategy (OS) to play against the team that only received the rules of the small-sided games. The comparisons among game scenarios were assessed via standardised mean differences. The comparison between WSI and DS revealed higher number of defensive actions, less space covered, and more distance covered in jogging for DS in comparison with WSI. The comparison between WSI and OS revealed more passes per ball possession, larger team length, larger space covered, lower distance covered walking, and more distance covered in jogging for OS in comparison with WSI. The results reinforce that coaches' previous instruction constrains the technical, tactical, and physical demands of small-sided games in football. The use of previous instruction regarding strategical and tactical behaviour allows highlighting the players' behaviour and ensures functional team performance.

KEY WORDS practice tasks, coaches' intervention; constraints, team sports, collective behaviour

$@$ MJSSMontenegro

COACHES' INSTRUCTION IN FOOTBALL SMALL-SIDED GAMES

http://mjssm.me/?sekcija=article\&artid=170

\section{Introduction}

The ability of team sports' coaches to manage task constraints in training practices is paramount to develop players and teams' performance (Potrac, Brewer, Jones, Armour, \& Hoff, 2000). Under this scope, some intervention models have been proposed in the literature in an attempt to identify the key knowledge and competences of successful sport coaches (Cushion, Armour, \& Jones, 2006). Among the different skills that a coach uses, the ability to communicate with players and to focus their attention on tasks is a key issue (Potrac et al., 2000) For instance, the correct design of practice tasks or the correct use of verbal instruction are fundamental skills for the development of physical, technical, and tactical skills (Aguiar, Botelho, Gonçalves, \& Sampaio, 2013; Travassos, Duarte, Vilar, Davids, \& Araújo, 2012; Williams \& Hodges, 2005).

Taking into consideration the constraint-lead approach, the coaches' ability to manipulate and intervene in training contexts according to specific competitions scenarios increases players' attentional focus and promotes the transference of behaviours between training and competition (Renshaw, Davids, Shuttleworth, \& 
Chow, 2009). Over the years, studies have been focused on the manipulation of rules in order to investigate its effects on technical, tactical and physical performance (Aguiar et al., 2013; Hill-Haas, Dawson, Impellizzeri, \& Coutts, 2011; Olthof, Frencken, \& Lemmink, 2017; Vilar et al., 2014). Such strategies, commonly used in small-sided games (SSG) contexts (i.e., manipulation of space, number of players, number of goals, corridors...) aims to trigger the emergence of individual behaviours that lead to functional team behaviours (Côté \& Gilbert, 2009; Davids, Araújo, Correia, \& Vilar, 2013).

Additionally, over the last years, some studies have analysed the effect of changes on instruction in the learning process of players and physical education students (Cordovil, Araujo, Davids, \& Gouveia, 2009; García, Sabido, Barbado, \& Moreno, 2013; Práxedes, Moreno, Sevil, García-González, \& Del Villar, 2016). Cordovil et al. (2009) showed that the manipulation of initial instruction in basketball (neutral, risk or conservative) promoted changes in interpersonal relationships among players and affected the way players explored space during 1x1 basketball tasks. García et al. (2013) studied the effects of instruction on the velocity and precision of handball shots in players of different levels and showed that instruction was most effective for less experienced players than for experienced ones. Also, Práxedes et al. (2016) recently suggested that the use of questioning in the practice of SSG allow the improvement of individual actions of players, such as the pass and the dribble.

In practice, the initial instruction is frequently used to manipulate training tasks according to the task goals and the expected offensive and defensive behaviour of teams (Cushion et al., 2006). In fact, initial instruction is one of the constraints most used by coaches when describing and defining the exercise aim and reinforcing the main possibilities of play. For that, task manipulation and initial instruction should be aligned with the strategic ideas of the coach to promote the transfer of team behaviours from training tasks to the competitive game environment (Renshaw et al., 2009). However, most of the time, coaches' perceptions did not match the obtained effects, and scientific knowledge is scarce regarding its effects on practice (Millar, Oldham, \& Donovan, 2011). To the best of our knowledge, no studies have been developed in football with the goal of understanding the effect of the initial instruction on the technical, tactical, and physical performance of players and teams.

Thus, the aim of this study was to assess the effects of coaches' strategic instruction on defensive and offensive performance in football small-sided games. Changes in technical actions, tactical behaviour, and external workload between teams that did not receive any strategic instruction, or received strategic instructions related to defensive or offensive behaviours were expected.

\section{Methods}

\section{Participants}

Sixteen semi-professional football players participated in the study (age: $23.9 \pm 5.4$ years old, body mass: $72.4 \pm 6 \mathrm{~kg}$, height: $1.79 \pm 0.6 \mathrm{~m}$ and playing experience: $11.2 \pm 5.3$ years). All players were part of the same club. The participants and coaching staff agreed with the protocol description and were notified that they could withdraw from the study at any time. Written informed consent was obtained from all participants. The investigation was approved by the local Institutional Research Ethics Committee and conformed to the recommendations of the 1964 Declaration of Helsinki.

\section{Procedures}

A cross-sectional field study was used to identify the effects of instructions in the technical, tactical, and physical behaviour of players and teams in small-sided games. Before the experimental session, there was a 15-min standardised warm-up based on running, ball possession, and dynamic stretching exercises. The outfield players were divided into two 7-a-side balanced competitive teams. Both teams received instructions regarding the rules of the small-sided games proposed.

Additionally, one team received instructions from the coach regarding the individual and collective tactical behaviour required for each exercise condition: (a) without strategic instruction (WSI); (b) Defensive strategy (DS); (c) Offensive strategy (OS). In the first exercise (WSI), both teams only received instructions regarding the rules of the small-sided game. In the second exercise (DS), one team was instructed to maintain the team compactness in the inner zones of the field in order to regain ball possession and explore counter-attacks to win the game. In the third exercise (OS), the instructed team was required to maintain ball possession and to only attack when a clear advantage was created. During the instruction, the coach highlighted the partial goals of the team and the distribution of players on the space that the team should promote to ensure the achievement of the proposed goals.

Each team played against the opponent twice in a randomised sequence in two different days (day 1: OS, WSI, DS and day 2: WSI, DS, OS), and data from outfield players were analysed comparing the performance of each team in each exercise. The two goalkeepers (GK) also participated in the protocol but were excluded from the data analysis. The 7-a-side games for testing the effects of instructions lasted for five minutes interspersed with three minutes of passive recovery and were played on a $62 \times 50$ metres in natural grass pitch, respecting the official football rules. 


\section{Data collection}

The technical actions of the players during the small-sided games that characterise defensive or attacking purposes were registered using a notational analysis system. The games were recorded using a video camera (CANON Legria HF G40) and the number of passes per ball possession (PBP) and the number of ball recoveries in inner zones (BR) were registered.

The dynamic players' positioning was gathered using a non-differential $5 \mathrm{~Hz}$ GPS system and used to compute both tactical and external workload variables. Tactical behaviour was analysed based on teams' length, teams' width, and teams' effective playing space (EPS) (computed using convex hull). The external workload was assessed through total distance covered by players and distance covered at different movement speed categories (Folgado, Duarte, Fernandes, \& Sampaio, 2014): 0.0-3.5 km/h (walking); 3.6-14.3 km/h (jogging); 14.4-19.7 $\mathrm{km} / \mathrm{h}$ (running); and $>19.8 \mathrm{~km} / \mathrm{h}$ (sprinting). All the variables were computed using dedicated routines in Matlab ${ }^{\circledR}$ software (MathWorks, Inc., Massachusetts, USA).

\section{Statistical Analysis}

Magnitude-based inferences and the precision of estimation were used to avoid the shortcomings of research approaches supported by the null-hypothesis significance testing (Batterham \& Hopkins, 2006). Prior to the game comparisons, all processed variables were log-transformed to reduce the non-uniformity of error. A descriptive analysis was performed using mean and standard deviations for each variable. The comparisons among game scenarios were assessed via standardised mean differences, computed with pooled variance and respective 90\% confidence intervals (Cumming, 2012; Hopkins, Marshall, Batterham, \& Hanin, 2009). Thresholds for effect sizes statistics were 0.2 , trivial; 0.6 , small; 1.2 , moderate; 2.0 , large; and $>2.0$, very large (Hopkins et al., 2009). Differences in means for both pairs of scenarios were also expressed and graphically represented in percentage units with $90 \%$ confidence limits (CL). The effect was reported as unclear if the CL overlapped the thresholds for the smallest worthwhile changes, which were computed from the standardised units multiplied by 0.2 . Magnitudes of clear effects were described probabilistically according to the following scale: $25-75 \%$, possible; 75-95\%, likely; 95-99\%, very likely; >99\%, most likely (Hopkins et al., 2009).

\section{Results}

As expected, the comparison between free game scenarios in competition revealed unclear effects on technical, tactical behaviour, and external workload.

The analysis of technical actions revealed the most likely large higher ball recoveries in inner zones for DS in comparison with WSI. Furthermore, likely moderate higher PBP for OS in comparison with WSI was observed. The other technical actions revealed unclear effects for the comparison between all the game scenarios (see Table 1 and Figure 1).

\begin{tabular}{|c|c|c|c|}
\hline \multirow{2}{*}{ Technical actions } & \multicolumn{3}{|c|}{ Game (mean \pm SD) } \\
\hline & WSI vs WSI & WSI vs DS & WSI vs OS \\
\hline Ball recoveries in inner zones & $2.3 \pm 2.1$ vs $3.3 \pm 1.9$ & $2.0 \pm 0.8$ vs $6.3 \pm 3.1$ & $1.3 \pm 0.4$ vs $2.0 \pm 0.8$ \\
\hline No passes per ball possession & $3.9 \pm 1.8$ vs $5.1 \pm 3.17$ & $3.9 \pm 2.2$ vs $3.3 \pm 1.2$ & $3.6 \pm 1.8$ vs $6.1 \pm 2.2$ \\
\hline
\end{tabular}

Note. WSI - without strategic instruction; DS - defensive strategy; OS - offensive strategy.

FIGURE 1 Standardized (Cohen) differences in technical variables according to the game scenarios' comparisons. Error bars indicate uncertainty in the true mean changes with $90 \%$ confidence intervals. Asterisks indicate the likelihood for the magnitude of the true differences in mean as follows: *likely; ${ }^{* * *}$ most likely
Technical actions

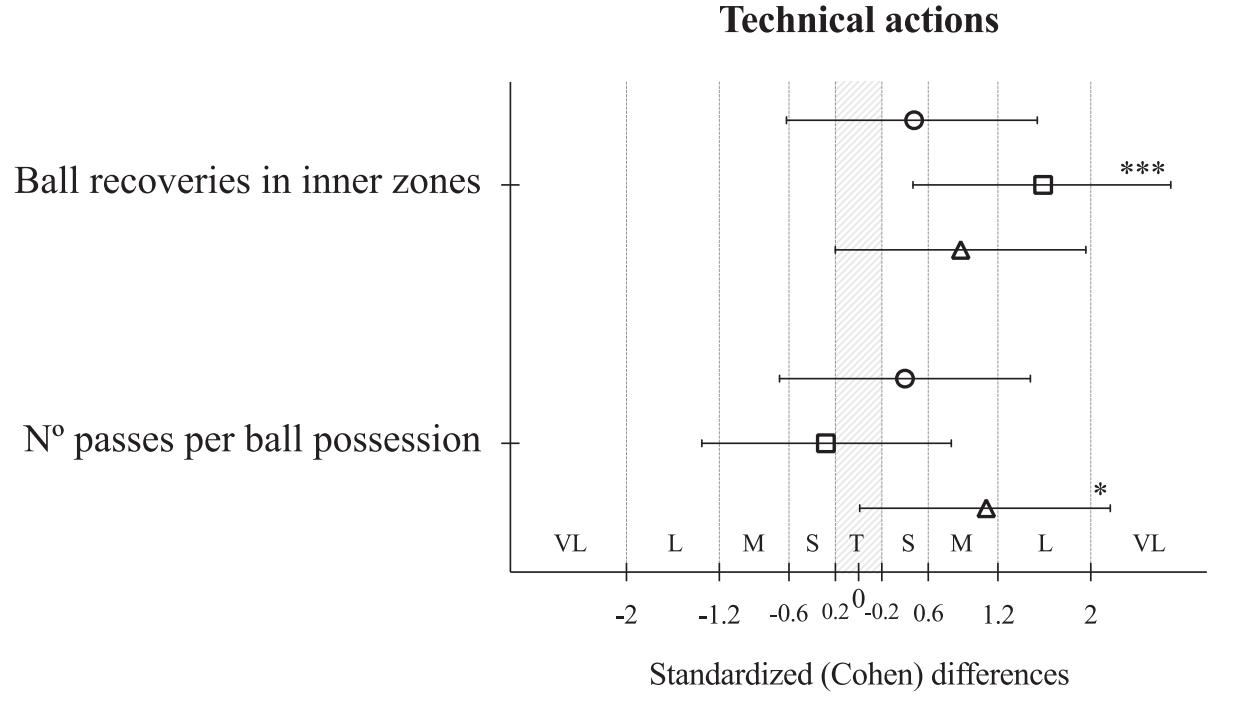

○ WSI vs WSI $\Delta$ WSI vs OS $\square$ WSI vs DS 
The analysis of tactical actions revealed likely moderate lower EPS for DS in comparison with WSI. Furthermore, very likely large higher team length and likely moderate higher EPS for OS in comparison with WSI were observed. The other tactical actions revealed unclear effects for the comparison between all the game scenarios (see Table 2 and Figure 2).

\begin{tabular}{|c|c|c|c|}
\hline \multirow{2}{*}{ Tactical behaviour } & \multicolumn{3}{|c|}{ Game (mean $\pm S D)$} \\
\hline & WSI vs WSI & WSI vs DS & WSI vs OS \\
\hline Team Length (m) & $20.2 \pm 4.1$ vs $20.7 \pm 2.1$ & $17.2 \pm 1.1$ vs $16.8 \pm 1.2$ & $18.2 \pm 2.4$ vs $21.2 \pm 1.7$ \\
\hline Team Width (m) & $32.6 \pm 4.7$ vs $33.8 \pm 2.4$ & $31.6 \pm 3.3$ vs $30.6 \pm 4.8$ & $29.6 \pm 2.4$ vs $31.3 \pm 3.4$ \\
\hline Effective playing space $\left(\mathrm{m}^{2}\right)$ & $398.1 \pm 79.3$ vs $403.2 \pm 46.2$ & $344.6 \pm 24.7$ vs $304.6 \pm 47.1$ & $318.4 \pm 55.6$ vs $382.9 \pm 57.7$ \\
\hline
\end{tabular}

\section{Tactical behaviour}

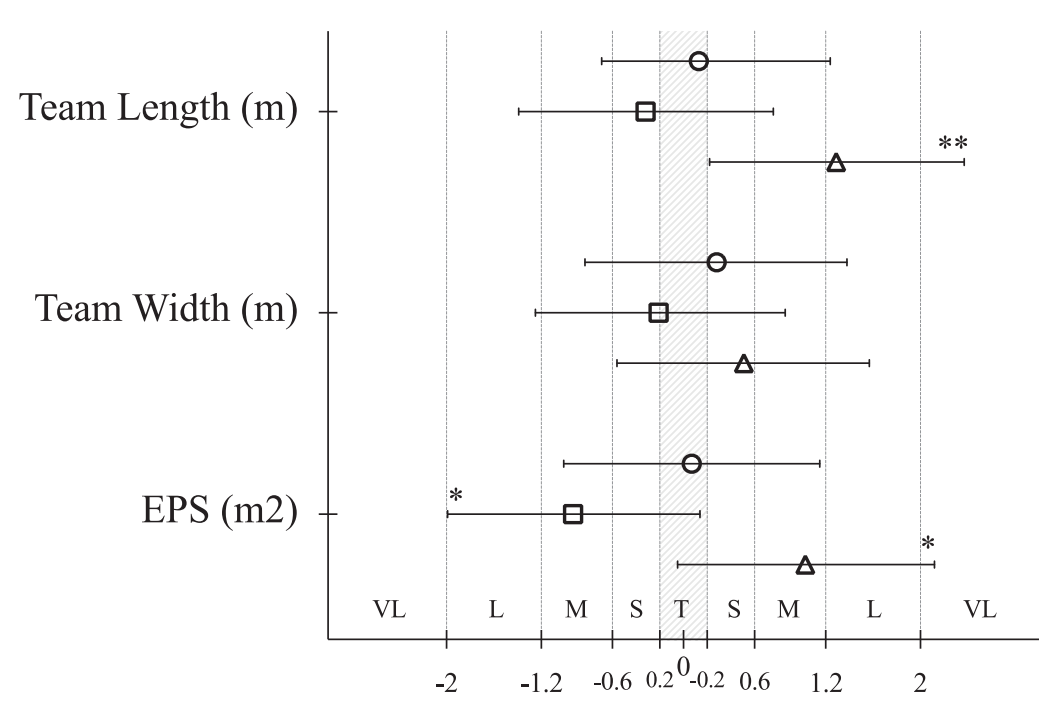

Standardized (Cohen) differences

$$
\text { ○ WSI vs WSI } \Delta \text { WSI vs OS } \square \text { WSI vs DS }
$$

FIGURE 2 Standardized (Cohen) differences in tactical variables according to the game scenarios' comparisons. Error bars indicate uncertainty in the true mean changes with $90 \%$ confidence intervals. EPS = effective playing space. Asterisks indicate the likelihood for the magnitude of the true differences in mean as follows: *likely; ${ }^{* *}$ very likely

The analysis of external workload revealed likely moderate higher distance covered in jogging for DS in comparison with WSI. Furthermore, likely moderate higher total distance covered, likely moderate lower distance covered walking, and most likely large higher distance covered jogging for OS in comparison with WSI were revealed. The other external load variables revealed unclear effects for the comparison between all the game scenarios (see Table 3 and Figure 3).

\begin{tabular}{|c|c|c|c|}
\hline \multirow{2}{*}{ External workload } & \multicolumn{3}{|c|}{ Game (mean $\pm S D)$} \\
\hline & WSI vs WSI & WSI vs DS & WSI vs OS \\
\hline $\begin{array}{l}\text { Total distance covered } \\
\qquad(\mathrm{m})\end{array}$ & $636.4 \pm 40.3$ vs $607.1 \pm 37.9$ & $567.9 \pm 42.2$ vs $591.1 \pm 60.9$ & $558.3 \pm 75.1$ vs $630.1 \pm 60.4$ \\
\hline $\begin{array}{l}\text { Dist covered Walking } \\
\quad(0-3.5 \mathrm{~km} / \mathrm{h})\end{array}$ & $33.5 \pm 5.9$ vs $34.4 \pm 5.8$ & $48.5 \pm 9.4$ vs $37.4 \pm 13.2$ & $49.3 \pm 14.3$ vs $34.8 \pm 11.6$ \\
\hline $\begin{array}{l}\text { Dist covered Jogging } \\
\quad(3.6-14.3 \mathrm{~km} / \mathrm{h})\end{array}$ & $487.3 \pm 31.4$ vs $470.1 \pm 36.1$ & $412.4 \pm 34.8$ vs $467.3 \pm 59.5$ & $404.5 \pm 61.7$ vs $489.4 \pm 46.5$ \\
\hline $\begin{array}{l}\text { Dist covered Running } \\
(14.4-19.7 \mathrm{~km} / \mathrm{h})\end{array}$ & $96.3 \pm 20.7$ vs $75.4 \pm 38.7$ & $83.5 \pm 32.9$ vs $69.6 \pm 9.7$ & $78.6 \pm 21.4$ vs $82.6 \pm 37.4$ \\
\hline $\begin{array}{l}\text { Dist covered Sprinting } \\
\quad(>19.8 \mathrm{~km} / \mathrm{h})\end{array}$ & $19.6 \pm 16.5$ vs $18.1 \pm 15.8$ & $23.4 \pm 10.8$ vs $16.6 \pm 14.1$ & $26.1 \pm 24.7$ vs $23.6 \pm 14.9$ \\
\hline
\end{tabular}




\section{External workload}

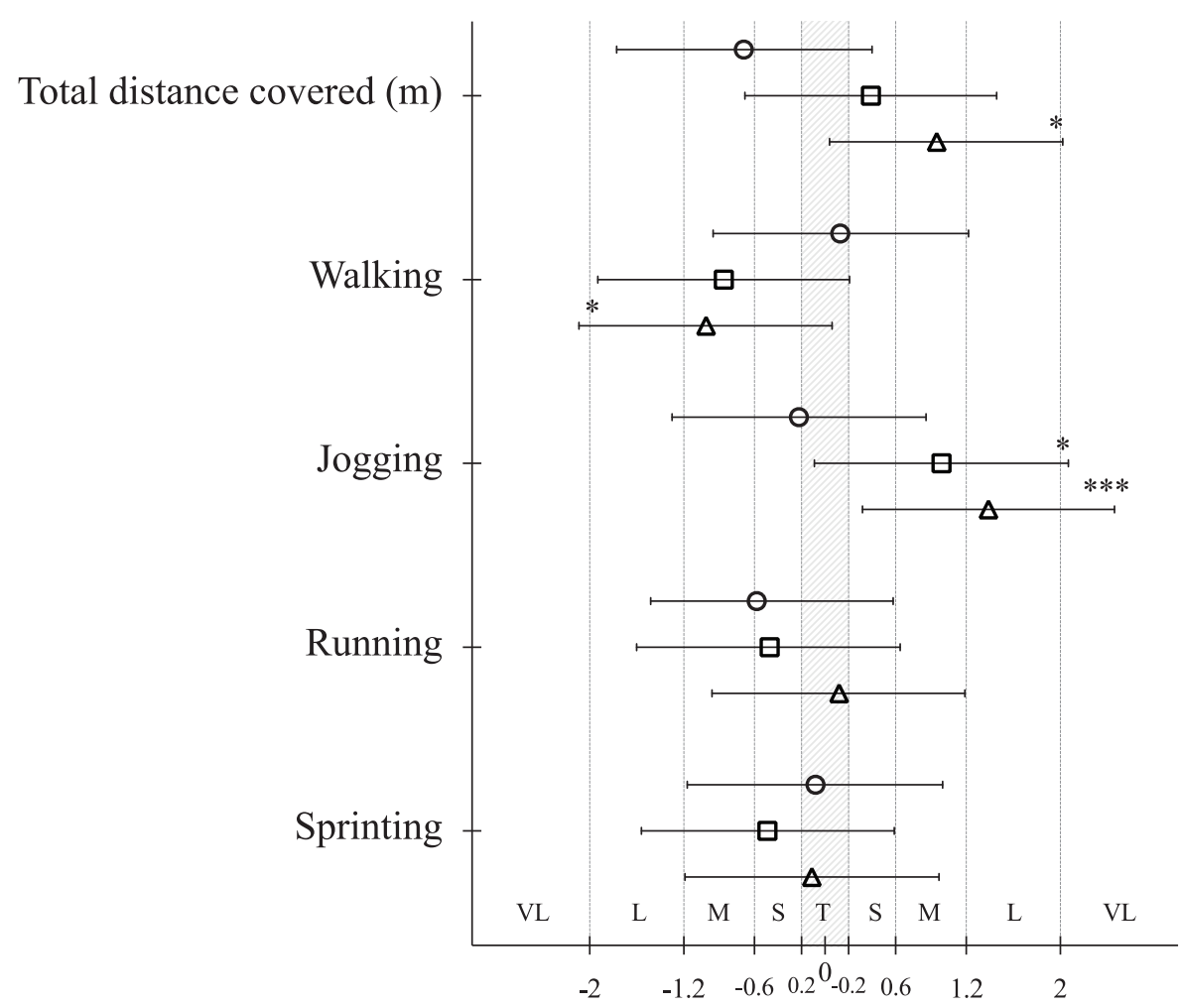

Standardized (Cohen) differences
○ WSI vs WSI
$\Delta$ WSI vs OS
WSI vs DS

FIGURE 3 Standardized (Cohen) differences in external workload variables according to the game scenarios' comparisons. Error bars indicate uncertainty in the true mean changes with $90 \%$ confidence intervals. Asterisks indicate the likelihood for the magnitude of the true differences in mean as follows: ${ }^{*}$ likely; ${ }^{* * *}$ most likely

\section{Discussion}

This study aimed to investigate the effects of changes on coaches' strategic instruction in technical actions, tactical behaviour, and external workload during football small-sided games.

Overall, the results showed that teams in which only WSI was used for both teams, the training tasks did not change technical, tactical and external load performances. The results confirmed that the use of coaches' strategic defensive and offensive instructions (i.e., DS and OS) constrains the technical, tactical, and physical performance of players and teams (Cushion et al., 2006; Millar et al., 2011). Regarding the team that received DS instructions, it was observed that they recovered more ball possessions in final pitch areas, decreased the space occupied, and increased the distance covered in jogging. Finally, the team that received OS instructions increased the number of passes and increased the space occupied in the pitch compared to the team that did not receive instruction. Surprisingly, this team increased the distance covered in jogging in comparison to the team WSI. These results highlight that the team that did not receive initial instruction explored individual and collective possibilities for action only based on situational information and without considering the strategic collective behaviour of the team (Renshaw et al., 2009). The definition of the strategic defensive or offensive behaviour allows that teams to direct the attention to taskwork with implicit coordination related with the goals previously defined in comparison with the team that did not receive such information (Eccles \& Tenenbaum, 2004).

Defensively, results suggest that after receiving DS instruction, teams perform more compactly throughout the game. The use of strategic instruction (e.g., maintain the team compactness in the inner zones of the pitch, in order to recover ball possession and explore counter-attacks) constraint the way that players perceive their own and teammates actions in order to potentiate their collective defensive behaviour (Silva, Garganta, Araujo, Davids, \& Aguiar, 2013). In defensive terms, the DS instruction also constrains the team only to try to recover ball possession in more favourable zones. Interestingly, results show that individual adjustments performed to achieve an optimal collective defensive behaviour have an impact on the external load, particularly on the jogging distance. These results are in line with previous investigations that show that when 
defensive behaviours are emphasised, players tend to compact the game space making their positioning more regular among teammates (Travassos, Gonçalves, Marcelino, Monteiro, \& Sampaio, 2014; Vilar et al., 2014). Thus, the initial verbal instruction focused on DS behaviours of the team can promote changes in the external load indexes of the exercises. Similar results were found through the handling of information about game and exercise time with impact on pacing (Ferraz et al., 2018) and on spatial-temporal relations between teams (Gonçalves et al., 2017).

With respect to instruction focused on OS, the results promote the use of a greater EPS, greater depth, as well as a greater number of passes per ball possession in comparison to the team without prior information. When defining that the OS of the team was to maintain ball possession and to attack the goal only when there was an advantage to creating a successful finalisation scenario, coach promoted a more supported game in a greater playing space. Inclusively, the greater depth of the team may be linked to more space between defensive lines and consequently the existence of more evident passing lines to progress in the field (Sgrò, Aiello, Casella, \& Lipoma, 2016).

As previously mentioned, highlighting the collective possibilities of play may promote the emergence of individual adaptations to collective demands. This emergent behaviour arises through the existence of shared affordances supported by existing contextual information and based on the intentionality of individual players to exploit the collective goal (Silva et al., 2013). The capacity of coaches to focus the attention of players on the spatial-temporal relations that support successful actions is key for this process (Cushion et al., 2006; Millar et al., 2011; Silva et al., 2013). In this case, it is possible to consider that the information provided by the coaches' previous instruction clearly constrain the exploration of the players' collective behaviour. However, this may not be valid for players and/or teams with different levels of skill or playing experience (Pritchard, Hawkins, Wiegand, \& Metzler, 2008).

As previously noted the external load of the team with previous instruction focused on OS was lower in walking but increased in jogging. To keep ball possession, the attackers are required to perform constant supportive movements to the ball carrier, which enhances collectively external load in jogging. Thus, it means that external load is strongly linked to the team's tactical aims and this should be considered when selecting instructions and task constraints (Hill-Haas et al., 2011; Owen et al., 2016; Sampaio, Lago, Gonçalves, Maçãs, \& Leite, 2013). These results reinforce the idea that the game pace of the team is determined by the collective goals of the team, with players adjusting the speed and precision of the collective actions to manage the playing space and to identify functional possibilities for action (Folgado, Duarte, Marques, \& Sampaio, 2015).

In summary, the coaches' instruction should be focused on the objective of the actions in order to promote individual and collective adaptations (Williams \& Hodges, 2005). The definition and manipulation of the defensive and offensive objectives linked to the initial instruction have a huge effect on the players and teams' performance and on the transfer of such behaviours to the competitive environment.

Nevertheless, it should be noted that the experimental design of this study presents some limitations that do not allow its generalisation to all contexts. It is not possible to measure the players' level of knowledge and the level of detail that each team needs to promote functional adaptations in their behaviour (García et al., 2013). The outcomes of this work must be considered and interpreted by each coach at the time of the definition of the previous instruction. Future investigations should consider larger samples, including more teams from different levels.

\section{Conclusion}

In conclusion, the present study revealed that coaches' instruction at the beginning of the practice tasks, constrains the technical, tactical, and physical demands of small-sided games in football. The use of strategic instruction allows highlighting the shared affordances that support the collective behaviour of teams to perform functionally. Thus, the use of appropriate coaches' instruction at the beginning of practice tasks could be paramount to focusing players on the key informational constraints that will support their individual and, consequently, collective solutions throughout the game. More than the definition of the moves required, coaches should highlight the goals that should be explored over the practice sessions to help players to discover and explore more functional technical and tactical solutions. The expected external load of each practice task should be aligned with the practice task manipulations and instructions to promote the right preparedness of players.

\section{REFERENCES}

Aguiar, M., Botelho, G., Gonçalves, B., \& Sampaio, J. (2013). Physiological responses and activity profiles of football small-sided games. Journal of Strength and Conditioning Research, 27(5), 1287-1294. doi:10.1519/ JSC.0b013e318267a35c

Batterham, A. M., \& Hopkins, W. G. (2006). Making Meaningful Inferences About Magnitudes. International Journal of Sports Physiology and Performance, 1(1), 50-57.

Cordovil, R., Araujo, D., Davids, K., \& Gouveia, L. (2009). The influence of instructions and body-scaling as constraints on decision-making processes in team sports. European journal of sport science, 9(3), 169-179. 
doi:10.1080/17461390902763417

Côté, J., \& Gilbert, W. (2009). An integrative definition of coaching effectiveness and expertise. International journal of sports science \& coaching, 4(3), 307-323.

Cumming, G. (2012). Understanding the New Statistics: Effect Sizes, Confidence Intervals, and Meta-Analysis. New York: Routledge, Taylor \& Francis Group.

Cushion, C. J., Armour, K. M., \& Jones, R. L. (2006). Locating the coaching process in practice: models 'for'and 'of'coaching. Physical education and sport pedagogy, 11(01), 83-99.

Davids, K., Araújo, D., Correia, V., \& Vilar, L. (2013). How small-sided and conditioned games enhance acquisition of movement and decision-making skills. Exercise and sport sciences reviews, 41(3), 154-161.

Eccles, D., \& Tenenbaum, G. (2004). Why an expert team is more than a team of experts: a social-cognitive conceptualization of team coordination and communication in sport. Journal of sport \& exercise psychology, 26(4), 542-560.

Ferraz, R., Gonçalves, B., Coutinho, D., Marinho, D. A., Sampaio, J., \& Marques, M. C. (2018). Pacing behaviour of players in team sports: Influence of match status manipulation and task duration knowledge. PLoS ONE, 13(2), e0192399. doi:10.1371/journal.pone.0192399

Folgado, H., Duarte, R., Fernandes, O., \& Sampaio, J. (2014). Competing with Lower Level Opponents Decreases Intra-Team Movement Synchronization and Time-Motion Demands during Pre-Season Soccer Matches. PLoS ONE, 9(5), e97145. doi:10.1371/journal.pone.0097145

Folgado, H., Duarte, R., Marques, P., \& Sampaio, J. (2015). The effects of congested fixtures period on tactical and physical performance in elite football. Journal of Sports Sciences, 33(12), 1238-1247. doi:10.1080/026 40414.2015.1022576

García, J. A., Sabido, R., Barbado, D., \& Moreno, F. J. (2013). Analysis of the relation between throwing speed and throwing accuracy in team-handball according to instruction. European journal of sport science, 13(2), 149-154.

Gonçalves, B., Esteves, P., Folgado, H., Ric, A., Torrents, C., \& Sampaio, J. (2017). Effects of Pitch AreaRestrictions on Tactical Behavior, Physical, and Physiological Performances in Soccer Large-Sided Games. Journal of Strength and Conditioning Research, 31(9), 2398-2408. doi:10.1519/JSC.0000000000001700

Hill-Haas, S., Dawson, B., Impellizzeri, M., \& Coutts, J. (2011). Physiology of Small-Sided Games Training in Football: A Systematic Review. Sports Medicine, 41(3), 199-220. doi:0112-1642/11/0003-0199

Hopkins, W. G., Marshall, S. W., Batterham, A. M., \& Hanin, J. (2009). Progressive Statistics for Studies in Sports Medicine and Exercise Science. Medicine and Science in Sports and Exercise, 41(1), 3-12. doi:Doi 10.1249/Mss.0b013e31818cb278

Millar, S.-K., Oldham, A. R. H., \& Donovan, M. (2011). Coaches' Self-Awareness of Timing, Nature and Intent of Verbal Instructions to Athletes. International journal of sports science \& coaching, 6(4), 503-513. doi:10.1260/1747-9541.6.4.503

Olthof, S. B., Frencken, W. G., \& Lemmink, K. A. (2017). Match-derived relative pitch area changes the physical and team tactical performance of elite soccer players in small-sided soccer games. Journal of Sports Sciences, 1-7.

Owen, A. L., Dunlop, G., Rouissi, M., Haddad, M., Mendes, B., \& Chamari, K. (2016). Analysis of positional training loads (ratings of perceived exertion) during various-sided games in European professional soccer players. International journal of sports science \& coaching, 11(3), 374-381.

Potrac, P., Brewer, C., Jones, R., Armour, K., \& Hoff, J. (2000). Toward an Holistic Understanding of the Coaching Process. Quest, 52(2), 186-199. doi:10.1080/00336297.2000.10491709

Práxedes, A., Moreno, A., Sevil, J., García-González, L., \& Del Villar, F. (2016). A preliminary study of the effects of a comprehensive teaching program, based on questioning, to improve tactical actions in young footballers. Perceptual and Motor Skills, 122(3), 742-756.

Pritchard, T., Hawkins, A., Wiegand, R., \& Metzler, J. N. (2008). Effects of Two Instructional Approaches on Skill Development, Knowledge, and Game Performance. Measurement in Physical Education and Exercise Science, 12(4), 219-236. doi:10.1080/10913670802349774

Renshaw, I., Davids, K., Shuttleworth, R., \& Chow, J. Y. (2009). Insights from ecological psychology and dynamical systems theory can underpin a philosophy of coaching. International Journal of Sport Pshychology, 40, 580-602.

Sampaio, J., Lago, C., Gonçalves, B., Maçãs, V., \& Leite, N. (2013). Effects of pacing, status and unbalance in time motion variables, heart rate and tactical behaviour when playing 5 -a-side football small-sided games. Journal of Science and Medicine in Sport, 17(2), 229-233.

Sgrò, F., Aiello, F., Casella, A., \& Lipoma, M. (2016). Offensive strategies in the European Football Championship 2012. Perceptual and motor skills, 123(3), 792-809.

Silva, P., Garganta, J., Araujo, D., Davids, K., \& Aguiar, P. (2013). Shared knowledge or shared affordances? Insights from an ecological dynamics approach to team coordination in sports. Sports Medicine, 43(9), 765-772. doi:10.1007/s40279-013-0070-9

Travassos, B., Duarte, R., Vilar, L., Davids, K., \& Araújo, D. (2012). Practice task design in team sports: Representativeness enhanced by increasing opportunities for action. Journal of Sports Sciences, 30(13), 1447-1454. doi:10.1080/02640414.2012.712716

Travassos, B., Gonçalves, B., Marcelino, R., Monteiro, R., \& Sampaio, J. (2014). How perceiving additional targets modifies teams' tactical behavior during football small-sided games. Human movement science, 
38, 241-250.

Vilar, L., Esteves, P., Travassos, B., Passos, P., Lago-Peñas, C., \& Davids, K. (2014). Varying Numbers of Players in Small-Sided Soccer Games Modifies Action Opportunities During Training. International Journal of Sports Science and Coaching, 9(5), 1007-1018.

Williams, A. M., \& Hodges, N. J. (2005). Practice, instruction and skill acquisition in soccer: Challenging tradition. Journal of Sports Sciences, 23(6), 637 - 650. doi:10.1080/02640410400021328 